\title{
DIAGNÓSTICO DA GESTÃO DOS RESÍDUOS SÓLIDOS EM DUAS UNIDADES ESCOLARES
}

\author{
André dos Santos ${ }^{1}$ \\ Valéria Sandra de Oliveira Costa ${ }^{2}$ \\ Thais Garcia Santos ${ }^{3}$
}

Resumo: Escolas são espaços, que geram diariamente uma grande quantidade de resíduos sólidos. Diante disso, existe a necessidade que instituições de ensino possuam um plano de gerenciamento de resíduos, de acordo com suas necessidades. A presente pesquisa avaliou a percepção do alunado sobre assuntos relacionadas a coleta seletiva e como é feito o gerenciamento dos resíduos sólidos em unidades escolares. A partir de um estudo descritivo e de uma abordagem quali-quantitativa, como forma investigativa, foram aplicados questionários semiestruturados com oito questões fechadas para 30 alunos do Ensino Fundamental (9ํano), 30 alunos do Ensino Médio ( $3^{\circ}$ ano), assim como oito questões para 18 professores das duas escolas públicas, ambas localizadas no município de São Joaquim do Monte-PE. A partir da metodologia aplicada, e dos dados obtidos, observamos que o problema do gerenciamento/gestão dos resíduos sólidos, é bem parecido nas duas escolas e mesmo havendo uma discrepância para algumas questões, existe um déficit em relação ao serviço de coleta seletiva e gerenciamento nessas instituições. Por outro lado, mesmo os professores trabalhando de forma efetiva com ações direcionadas de Educação Ambiental, reciclagem e coleta seletiva, a problemática toma dimensões maiores, pois na própria cidade o serviço de coleta municipal, faz a destinação de todos os resíduos, inclusive os escolares em terreno baldio, sem nenhuma condição de tratamento/reciclagem. A fim de sensibilizar as duas turmas, foram realizadas palestras voltadas para questão do descarte sustentável, importância da coleta seletiva, reciclagem e principalmente sobre o incentivo à mudança de atitudes e comportamento perante o meio ambiente.

Palavras-chave: Ambiente Escolar; Educação Ambiental; Lixo Escolar.

\footnotetext{
${ }^{1}$ Universidade Federal de Pernambuco. E-mail: biologistsantosandre@gmail.com

2 Universidade Federal de Pernambuco. E-mail: costavso@yahoo.com.br

${ }^{3}$ Universidade Federal de Minas Gerais. E-mail: tgsbio@hotmail.com
} 


\section{Introdução}

Desde as civilizações antigas, o homem nômade caçava, pescava e produzia resíduos sólidos. Quando estes recursos se tornavam escassos, migravam para outros locais e deixavam seus "lixos" que passavam a ser dispostos na natureza. Após alguns séculos, a revolução industrial contribuiu gradativamente para o aumento da produção de resíduos sólidos em todo o mundo. Estes por sua vez ainda são descartados em ambientes inapropriados e geram graves consequências para o meio ambiente, como a contaminação do solo e lençóis freáticos, assoreamento dos rios e a proliferação de insetos e roedores vetores de doenças (GOUVEIA, 2012).

No Brasil, segundo dados da Associação Brasileira das Empresas de Limpeza Pública e Resíduos (ABRELPE), estima-se que a geração de resíduos sólidos per capita seja de $1.035 \mathrm{~kg} /$ habitantes/dia (ABRELPE, 2017). Neste sentido, é imprescindível que políticas públicas sejam implantadas, nos municípios que visem diagnosticar e atuar na coleta, transporte e destinação final dos resíduos sólidos de forma ambientalmente adequada. Também é preciso que a própria sociedade compreenda a importância dos resíduos sólidos, uma vez que a coleta de materiais recicláveis pode gerar lucros e diminuir os impactos ao meio ambiente (RIBEIRO et al., 2014).

As escolas por sua vez, são núcleos que geram diversos tipos de resíduos, e por isto é desejável que o ambiente escolar tenha um plano de gerenciamento adequado. Para isto, alunos e professores precisam ser sensibilizados, para que desenvolvam ações que promovam mudanças no pensar e agir, quando se tratar de descarte de resíduos. Ainda, a coleta seletiva torna-se uma medida educativa, que pode provocar mudanças positivas e minimizar os impactos negativos decorrentes da geração de lixo.

Inserir esta conscientização no ambiente escolar é sem dúvida um dos melhores meios para a formação de sujeitos ecológicos, uma vez que grande parte dos desequilíbrios ambientais estão relacionados a condutas e hábitos incorretos, que podem ser mudados através de simples ações no dia a dia (FÉLIX, 2007).

Portanto, é imprescindível conhecer a gestão dos resíduos sólidos em escolas públicas, uma vez que os resultados podem contribuir, para o desenvolvimento de um plano municipal de gestão integrada, e consequentemente para a implantação do serviço de coleta nas escolas.

\section{Definição de Resíduos Sólidos e Sua Política Nacional}

Uma grande parcela da poluição do meio ambiente é composta por resíduos sólidos, que de acordo com a Lei 12.305/10 da Política Nacional de Resíduos Sólidos (PNRS) apresentam uma classificação em função de sua origem e periculosidade (BRASIL, 2010) (Quadro 1). Com base no artigo $3^{\circ}$ da Política Nacional de Resíduos Sólidos, é denominado Resíduo Sólido como: 
Material, substância, objeto ou bem descartado resultante de atividades humanas em sociedade, a cuja destinação final se procede, se propõe proceder ou se está obrigado a proceder, nos estados sólido ou semissólido, bem como gases contidos em recipientes e líquidos cujas particularidades tornem inviável o seu lançamento na rede pública de esgotos ou em corpos d'água, ou exijam para isso soluções técnica ou economicamente inviáveis em face da melhor tecnologia disponível (BRASIL, 2010).

Quadro 1: Classificação dos Resíduos Sólidos. Fonte: Brasil (2010).

\begin{tabular}{|c|l|}
\hline \multirow{5}{*}{ Origem } & Domiciliares: atividades domésticas em residências urbanas; \\
\cline { 2 - 3 } & $\begin{array}{l}\text { Limpeza Urbana: varrição, limpeza de logradouros e vias públicas e outros } \\
\text { serviços; }\end{array}$ \\
\cline { 2 - 3 } & Comerciais: os gerados nessas atividades; \\
\cline { 2 - 3 } & Serviços Públicos de Saneamento Básico: os gerados nessas atividades; \\
\cline { 2 - 3 } & $\begin{array}{l}\text { Construção Civil: construções, reformas, reparos, demolições, preparação e } \\
\text { escavações de terrenos para obras; }\end{array}$ \\
\cline { 2 - 3 } & $\begin{array}{l}\text { Agrossilvopastoris: atividades agropecuárias e silviculturais incluídos } \\
\text { insumos utilizados nessas atividades; }\end{array}$ \\
\cline { 2 - 3 } Periculosidade & $\begin{array}{l}\text { Serviços de Transportes: portos, aeroportos, terminais alfandegários, } \\
\text { rodoviários, ferroviários, e passagens de fronteira; }\end{array}$ \\
\cline { 2 - 3 } & Mineração: pesquisa, extração ou beneficiamento de minérios; \\
\cline { 2 - 3 } & Industriais: processos produtivos e instalações industriais. \\
\hline & $\begin{array}{l}\text { Perigosos: inflamabilidade, corrosividade, reatividade, toxicidade, } \\
\text { patogenicidade, carcinogenicidade, teratogenicidade e mutagenicidade com } \\
\text { risco a saúde pública ou a qualidade ambiental; }\end{array}$ \\
\cline { 2 - 2 } & Não Perigosos: todos aqueles que não são enquadrados na alínea anterior. \\
\hline
\end{tabular}

A PNRS objetiva a promoção da gestão correta dos resíduos sólidos, através do desenvolvimento de práticas sustentáveis que diminuam os impactos promovidos pela destinação de rejeitos de forma inadequada (OLIVEIRA; PINTO JÚNIOR, 2018). Esta lei, ainda define que as instituições públicas, e que são responsáveis pelo gerenciamento dos resíduos produzidos, e, no entanto, grande parte das instituições de ensino ainda não dispõe de serviços de coleta seletiva e reciclagem. A falta de ações práticas de conscientização, e da própria gestão escolar, contribui para que resíduos sólidos e orgânicos sejam destinados ao lixo comum e recolhidos junto a coleta municipal sem nenhum tratamento.

\section{Gestão e Gerenciamento de Resíduos Sólidos}

O gerenciamento de resíduos sólidos envolve a coleta, transporte, tratamento e destinação final ambientalmente adequada. A criação da PNRS tem como foco a redução da disposição incorreta dos resíduos sólidos, no entanto, a gestão correta ainda é escassa, uma vez que o poder público não incentiva o seu cumprimento integral. Neste sentido, é desejável que o setor público federal, estadual e municipal coopere por meio da implantação de políticas públicas, que visem identificar e solucionar a gestão dos resíduos sólidos urbanos e escolares, com a finalidade de promover menores danos ao meio ambiente. 
Atualmente, a grande maioria dos resíduos sólidos, é destinada a lixões sem tratamento, impactando negativamente a saúde pública. Um planejamento integrado nos municípios pode minimizar este problema atual, sendo a instalação de aterros sanitários, considerada ainda uma alternativa paliativa para minimizar os impactos ao meio ambiente (PORTELLA; RIBEIRO, 2014).

Partindo dessa temática, é preciso que outros meios sejam implantados para diminuir o volume de lixo nos aterros, é necessário que ocorra primeiramente uma redução na geração de resíduos sólidos, se não for possível ainda assim, muitos materiais podem ser reutilizados. Neste caso a reutilização poderá ser feita, com práticas de coleta convencional e seletiva, esta última pode ser um fator indispensável, para que ocorra o processo de reciclagem/reutilização. Quando a reutilização e a reciclagem não são possíveis, é importante que seja feito um tratamento através da incineração, compostagem ou separação, para que o mínimo de rejeitos seja destinado aos aterros sanitários (BARROS, 2013).

É necessário um planejamento mais efetivo, por parte de todas as esferas de governo em curto prazo, visando reduzir a poluição do meio ambiente, e incentivando a reciclagem e reutilização dos resíduos sólidos. Para isto, é importante que um plano municipal de gerenciamento integrado seja implantado pelo governo municipal nas cidades. Vilhena (2018) destaca a importância de medidas de Educação Ambiental, para sensibilizar alunos e cursos de formação continuada para funcionários públicos, a fim de articular ações para o tratamento do lixo municipal e incentivar a implantação de cooperativas de catadores.

Diante disto, é preciso a responsabilidade dos poderes públicos e privado, e principalmente dos consumidores, para que possam diminuir os efeitos negativos, provocados a saúde pública e ao meio ambiente, causados pelo mal gerenciamento e gestão de resíduos sólidos.

Visto que a Educação Ambiental é uma prática, que atua na formação de cidadãos conscientes e críticos relacionados aos assuntos socioambientais, fazse necessário sua inserção em todos os níveis e modalidades do processo educativo, seja em carácter formal e não formal como um componente essencial e permanente da educação nacional, como menciona o art. $2^{\circ}$ da Lei 9.795/1999 (BRASIL, 1999), pois em muitas escolas a temática e vista de maneira simplista onde professores se atentam apenas as questões de preservação e conservação ambiental, deixando de lado outras problemáticas que merecem atenção (SANTOS et al., 2017).

A Educação Ambiental se constitui como um instrumento, capaz de sensibilizar a comunidade escolar, e fazer com que os alunos se tornem seres conscientes e críticos em relação ao meio ambiente, principalmente quando o problema está associado ao gerenciamento dos resíduos sólidos escolares. Para Soares et al. (2007), a Educação Ambiental, tem que estar inserida nos planos de gerenciamento de resíduos sólidos, principalmente nos programas de coleta seletiva, uma vez que a comunidade passa a receber diversas informações sobre o assunto e aprende a contribuir de maneira bastante positiva no processo de gestão.

Revbea, São Paulo, V. 14, № 4: 25-39, 2019. 
Ações de Educação Ambiental tornam-se uma ótima maneira para incentivar alunos a fazerem o gerenciamento correto no âmbito escolar, visto que muitas escolas lidam constantemente com o mau gerenciamento dos resíduos sólidos que são produzidos durante os horários de funcionamento. Parte desses problemas está relacionada à ausência de ações, e medidas de Educação Ambiental por parte dos professores e equipe de gestão, que poderiam ser minimizados com a adoção de estratégias eficazes, visando a mudança de comportamento no âmbito escolar.

Nesse sentido, objetiva-se com esta pesquisa diagnosticar como é realizado o gerenciamento de resíduos e práticas relacionadas à coleta seletiva e Educação Ambiental em duas escolas públicas, localizadas no município de São Joaquim do Monte-PE.

\section{Metodologia}

\section{Caracterização da Área de Estudo}

Este estudo foi desenvolvido em duas escolas públicas em São Joaquim do Monte-PE, município inserido na Mesorregião do Agreste pernambucano a uma latitude $08^{\circ} 25^{\prime} 57^{\prime \prime}$ sul e a uma longitude $35^{\circ} 48^{\prime} 16^{\prime \prime}$ oeste, com cerca de 21.000 habitantes (IBGE, 2017). A Escola Municipal Oswaldo Benício Vaz Cavalcanti, atua na educação do ensino fundamental e a EREM Frei Epifânio no ensino médio. Ambas foram às escolhidas para o desenvolvimento da pesquisa (Figura 1).
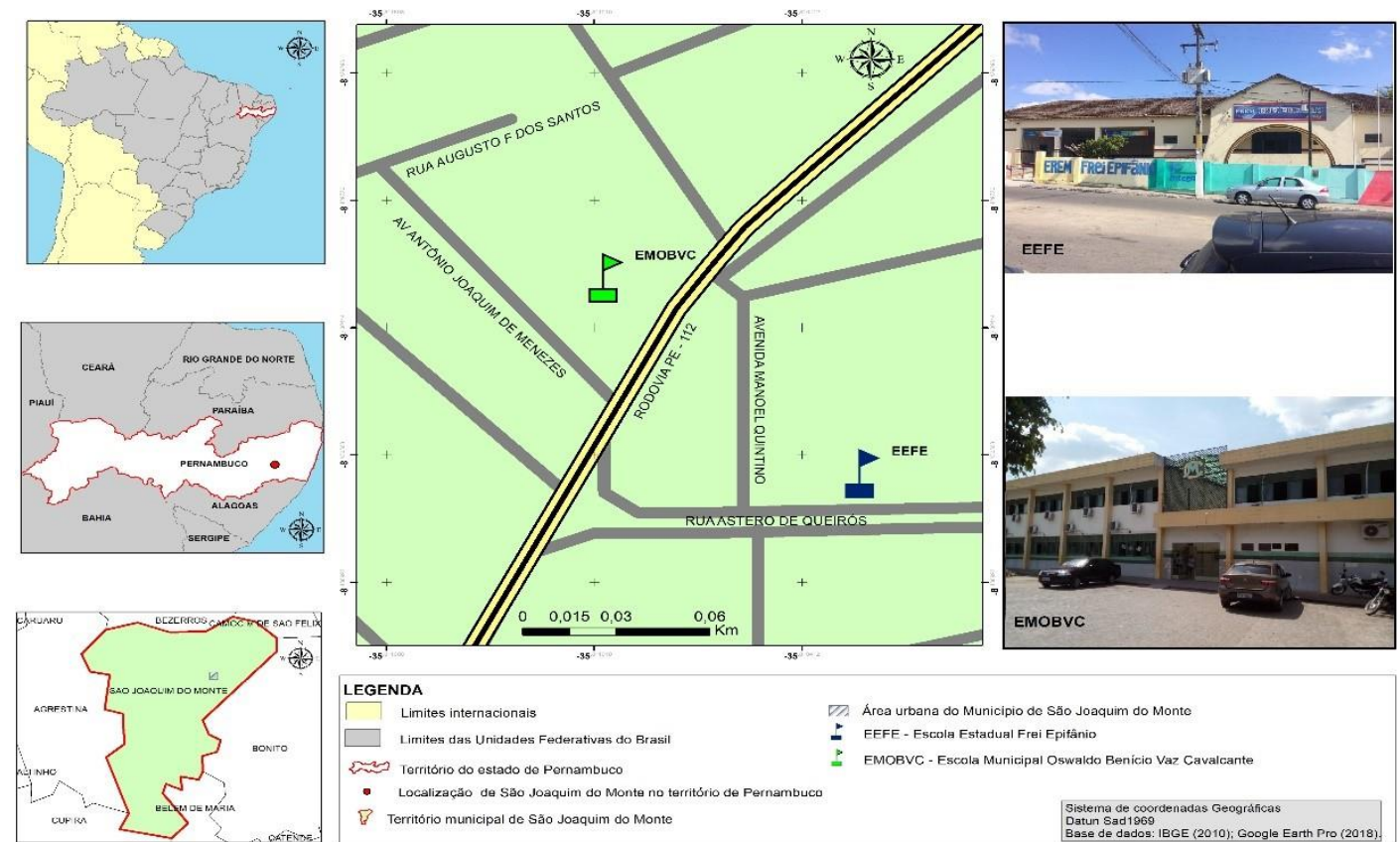

1. Território municipal de São Joaquim do Monte

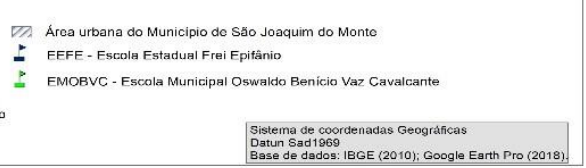

Figura 1: Mapa da localização municipal e intra-urbana das escolas no município de São Joaquim do Monte/PE. Fonte: Os autores.

As instituições contam com um quadro de professores efetivos e contratados com formação em magistério, graduados, especialistas e mestres. 
As escolas participam de um projeto político pedagógico atualizado e revisado anualmente segundo seus gestores, e uma gestão democrática e participativa onde funcionários, comunidade, professores, alunos, pais, direção e toda equipe pedagógica são considerados sujeitos ativos no processo de gestão.

\section{Métodos Instrumentos e Coleta de Dados da Pesquisa}

O estudo configurou-se como uma pesquisa de campo descritiva exploratória dentro de uma abordagem quali-quantitativa, uma vez que procurou investigar com maior amplitude e aprofundamento 0 diagnóstico do gerenciamento dos resíduos sólidos escolares e prática de coleta seletiva no ambiente escolar. Thiollent (1986, p. 48) explica que "a fase exploratória consiste em descobrir o campo de pesquisa, os interessados e suas expectativas e estabelecer um primeiro levantamento ou "diagnóstico" da situação, dos problemas prioritários e de eventuais ações".

Para Gil (2012, p. 28), "as pesquisas descritivas têm como objetivo primordial descrição das características de determinada população ou fenômeno ou, então, o estabelecimento de relações entre variáveis". Em relação aos métodos que foram utilizados para coleta de dados, a pesquisa se caracterizou como bibliográfica e de levantamento.

A metodologia utilizada foi baseada inicialmente, com pesquisa bibliográfica e documental nas bases de dados SciELO, Google Scholar, Scopus, Periódicos Capes, Repositórios institucionais, Leis e Decretos, utilizando os seguintes termos de indexação: "Resíduos Sólidos", "Lixo Escolar", "Educação Ambiental" e "Coleta Seletiva Escolar".

Posteriormente, foi realizada a pesquisa de campo, com visitas in loco onde ocorreram às observações diretas e entrevistas com cerca de 30 alunos do 9o ano do Ensino Fundamental, da Escola Municipal Oswaldo Benício Vaz Cavalcanti e 30 alunos do $3^{\circ}$ ano do Ensino Médio, da EREM - Frei Epifânio, as entrevistas se estenderam também a 18 professores dessas escolas. Os questionários foram semiestruturados com questões fechadas (resposta do tipo sim ou não) e algumas abertas para os professores (onde o entrevistado comenta o assunto). A coleta de dados foi realizada no segundo semestre de 2018, nos meses de setembro e outubro. Para Minayo (2012, p. 64), "a entrevista tem por objetivo construir informações pertinentes para um objeto de pesquisa, e abordagem pelo entrevistador, de temas igualmente pertinentes com vistas a este objetivo".

Após a realização das entrevistas, foi ministrada em ambas as escolas, uma palestra intitulada "Gerenciamento de Resíduos Sólidos: importância da coleta seletiva e reciclagem em espaços formais".

Com a obtenção dos dados na coleta, os resultados foram compilados e analisados com base em um enfoque quali-quantitativo, no programa Microsoft Excel${ }^{\circledR}(2016)$ e os dados foram apresentados em tabelas para caracterização amostral, utilizando a frequência relativa (FR). 


\section{Questões Éticas}

Durante o desenvolvimento da pesquisa várias questões éticas foram levadas em conta: i) toda e qualquer informação divulgada do questionário foi feita de forma anônima; ii) os participantes das entrevistas responderam de forma voluntária; iii) todos os dados foram apresentados de maneira coletiva e não individual; e iv) proteção do banco de dados pelos pesquisadores; v) assinatura de termo de consentimento livre esclarecido - TCLE.

\section{Resultados e discussão}

A pesquisa alcançou um universo de 60 alunos e 18 professores que lecionam nas respectivas escolas.

Ao analisar os questionários aplicados aos alunos e professores das duas escolas, foi perceptível que ambas as escolas apresentam alguns aspectos semelhantes relacionados ao gerenciamento dos seus resíduos sólidos e coleta seletiva no ambiente escolar (Tabela 1).

Tabela 1: Percepção sobre a gestão dos resíduos sólidos escolares de alunos de duas escolas públicas em São Joaquim do Monte-PE. Fonte: Elaborado a partir de dados obtidos nesta pesquisa, 2018.

\begin{tabular}{|c|c|c|c|c|}
\hline Questão & & itude 0 & posta & \\
\hline ATITUDE DE RESPOSTA & 1 & 2 & 3 & 4 \\
\hline Q1. Você sabe o que são resíduos sólidos? & & & & \\
\hline 9 ano & $30 \%$ & $47 \%$ & $23 \%$ & - \\
\hline 3o ano & $50 \%$ & $17 \%$ & $33 \%$ & - \\
\hline Q2. Na sua escola existe orientação para separar os resíduos? & & & & \\
\hline 9 ano & $63 \%$ & $37 \%$ & - & - \\
\hline 3 ano & $17 \%$ & $83 \%$ & - & - \\
\hline $\begin{array}{l}\text { Q3. Na sua escola existe coletores diferentes para cada tipo } \\
\text { de resídun? }\end{array}$ & & & - & - \\
\hline 9o ano & $0 \%$ & $100 \%$ & - & - \\
\hline 3ㅇ ano & $0 \%$ & $100 \%$ & - & - \\
\hline $\begin{array}{l}\text { Q4. Você sabia que grande parte dos resíduos escolares } \\
\text { podem ser reutilizados, reciclados ou reaproveitados? }\end{array}$ & & & & \\
\hline $9 \circ$ ano & $80 \%$ & $4 \%$ & $16 \%$ & - \\
\hline 3ㅇ ano & $70 \%$ & $20 \%$ & $10 \%$ & - \\
\hline $\begin{array}{l}\text { Q5. Você sabia que é importante separar os resíduos nos } \\
\text { diferentes setores da escola? }\end{array}$ & & & & \\
\hline $9 \circ$ ano & $87 \%$ & $13 \%$ & - & - \\
\hline 3ㅇ ano & $70 \%$ & $30 \%$ & - & - \\
\hline $\begin{array}{l}\text { Q6. Você sabe como é feito o gerenciamento dos resíduos } \\
\text { sólidos escolares desde a coleta até o destino final? }\end{array}$ & & & & \\
\hline 9o ano & $3 \%$ & $67 \%$ & $3 \%$ & - \\
\hline 3 ano & $0 \%$ & $86 \%$ & $14 \%$ & - \\
\hline $\begin{array}{l}\text { Q7. Você já recebeu orientação dos professores ou equipe de } \\
\text { gestão para fazer o descarte adequado dos resíduos? }\end{array}$ & & & & \\
\hline 9 ano & $36 \%$ & $44 \%$ & $20 \%$ & - \\
\hline 3ㅇ ano & $13 \%$ & $57 \%$ & $30 \%$ & - \\
\hline $\begin{array}{l}\text { Q8. A escola desenvolve projetos ou outra atividade ligada a } \\
\text { reciclagem e coleta seletiva de resíduos? }\end{array}$ & & & & \\
\hline $9 \circ$ ano & $23 \%$ & $77 \%$ & - & - \\
\hline $3^{\circ}$ ano & $40 \%$ & $60 \%$ & - & - \\
\hline
\end{tabular}

${ }^{*} \mathrm{Q}$ : questionamento/questão; **1- sim; 2- não 3- já ouvi falar; e 4- não respondeu. 
Ao serem questionados sobre resíduos sólidos, $50 \%$ dos alunos do $3^{\circ}$ ano responderam que tinham conhecimento sobre a temática e menos da metade dos alunos do 9a ano, ou seja, 30\% afirmaram ter conhecimento sobre resíduos sólidos. Quando foram indagados se recebiam dentro da escola alguma orientação para separar os resíduos sólidos, o quantitativo para resposta sim, foi de $63 \%$ para alunos do $9^{\circ}$ ano e $17 \%$ para o $3^{\circ}$ ano. Com estes resultados podese perceber que apesar das escolas orientarem os educandos em separar os resíduos, $70 \%$ dos alunos não sabem o que são resíduos sólidos, sendo necessários professores e equipe de gestão trabalhar essa temática de maneira mais efetiva em todos os níveis de ensino.

Stangherlin e Spech (2014) ao estudarem a percepção de alunos do Ensino Fundamental I ( $4^{\underline{a}}$ e $5^{\underline{a}}$ séries), relatam que eles não tinham conhecimento sobre o termo "resíduos sólidos". Em se tratando do Ensino Fundamental II ( $9^{\circ}$ ano) em que receberam orientação para separar resíduos sólidos. Provavelmente, eles tenham fixado o termo "lixo" em vez de "resíduos sólidos".

A partir dos resultados coletados, pode-se constatar que ambas as escolas não apresentam coletores seletivos, para separar os diversos tipos de resíduos sólidos gerados no dia-a-dia, e que os alunos descartam seu "lixo" nos coletores comuns sem separar, e até mesmo o lixo orgânico é misturado ao comum. O resultado desse questionamento para as duas escolas foi de $100 \%$, embora os alunos recebam alguma orientação dos profissionais sobre separação dos resíduos sólidos, fica difícil implantar a coleta seletiva sem a disposição de coletores apropriados.

Situação desse tipo foi relatada por Almeida (2018) quando realizou um estudo sobre a gestão de resíduos sólidos em escolas públicas em Belo Jardim/PE. Este pesquisador relata que em algumas instituições não se faz coleta seletiva, e outras a coleta seletiva é considerada apenas satisfatória, chegando à conclusão de que em todas as escolas estudadas por ele, se faz necessário a otimização das ações direcionadas à gestão de resíduos sólidos, bem como de adotar novas práticas que favoreçam a implantação de um sistema de coleta seletiva eficiente, associado a projetos e programas voltados à redução, ao reaproveitamento e à reciclagem de resíduos.

No presente estudo, a maioria dos alunos entrevistados tinha conhecimento que grande parte dos resíduos escolares podiam ser reutilizados, reciclados ou reaproveitados. E apesar de reconhecerem a importância de separar os resíduos nos diversos setores da escola, desconhecem como é feito o processo de gestão, desde a coleta até sua destinação final (Tabela 1). Porém mesmo estando cientes disso, não há coleta seletiva em ambas as instituições, sendo todo gerenciamento do lixo escolar, realizado através do serviço de coleta municipal e a disposição final é feita sem nenhum tratamento, em um terreno baldio a céu aberto afastado do município de São Joaquim do Monte-PE.

Sobre quando questionados na questão $n^{\circ} 6$, se sabiam como é feito o gerenciamento dos resíduos sólidos $67 \%$ dos alunos do $9^{\circ}$ ano e $86 \%$ do $3^{\circ}$ ano 
responderam de forma negativa. Isto é, a maioria dos alunos desconhecia como é feito o processo de gerenciamento, desde a coleta até sua destinação final.

Segundo dados colhidos na prefeitura municipal de São Joaquim do Monte-PE, com o secretário de obras, viação e urbanismo que responde pelas questões relacionadas ao meio ambiente e gerenciamento de resíduos sólidos urbanos. O município conta com um plano municipal de gerenciamento de resíduos sólidos ainda inacabado, que visa a transferência de todo lixo recolhido para um aterro sanitário.

Mesmo a minoria dos alunos recebendo orientação dos professores e equipe gestora, para fazer o gerenciamento correto dos resíduos sólidos escolares, essa prática não se estende a comunidade. E para as ações realizadas no ambiente escolar, $44 \%$ dos alunos do $9^{\circ}$ ano afirmaram que não recebem nenhum tipo de orientação, e $57 \%$ dos entrevistados do $3^{\circ}$ ano também negaram ter esse tipo de informação, isso explica por que a coleta seletiva nessas instituições ainda é algo utópico.

Aliado a este resultado, nas visitas in loco nas duas escolas, foi constatado uma grande quantidade de lixo, jogado no chão do pátio e corredores durante 0 intervalo, embalagens de papéis e plásticos de lanches. Provavelmente, os alunos de ambas as instituições receberam orientações sobre como descartar o lixo de forma adequada, e o que está ocorrendo e que a percepção deles em relação ao ambiente escolar ainda não tenha sido concretizada. Segundo Bezerra et al. (2014) a percepção ambiental é tomada de consciência das problemáticas ligadas ao ambiente. Ou seja, é quando o indivíduo percebe o ambiente em que está inserido e, assim, se capacitam para cuidar e defendê-lo.

Em relação ao desenvolvimento de projetos, e ações de Educação Ambiental atividade ligada à reciclagem e coleta seletiva de resíduos, indagação da questão no 8, os alunos apresentaram um percentual bastante baixo em relação a esse tipo de atividade no ambiente escolar, $77 \%$ dos alunos do no 9 o ano afirmaram que a escola não desenvolve esse tipo de projeto ou ação, e $60 \%$ no $3^{\circ}$ ano também não desenvolve nenhum tipo de ação interdisciplinar, que seja promovido pelos professores ou equipe de gestão em sala de aula ou de maneira coletiva, envolvendo a comunidade escolar. Estes resultados contrastam ao que é recomendado pelos Parâmetros Curriculares Nacionais ( $P C N)$, já que enfatizam a importância de os educadores trabalharem os temas transversais nas escolas, ao passo que a temática meio ambiente e saúde devem estar inseridas no currículo da educação básica (PCN, 1997).

Com os resultados obtidos através dos questionamentos feitos ao alunado, pode ser inferido que as duas instituições de ensino, apresentam dificuldade para trabalhar com as questões ambientais, principalmente sobre os resíduos sólidos ou lixo. E uma vez que grande parte dos alunos, não exercem práticas relacionadas a questões ambientais, incluídas na Educação Ambiental escolar, que visem melhorias para escola e o meio ambiente, pode ser 
depreendido que os professores que trabalham temas referentes à coleta seletiva e reciclagem, vêm fazendo um trabalho de maneira bastante singular.

Neste sentido, Bezerra et al. (2014) explicam que diversos estabelecimentos de ensino, têm dificuldades para delinear com objetividade os princípios da Educação Ambiental e as metodologias mais adequadas para sua realidade escolar. Os professores precisam ir além ao processo educativo dos alunos, incentivando o alunado a práticas educacionais diversificadas como uma forma de impulsioná-los a uma percepção da realidade em que estão inseridos, Meirelles e Santos (2005, p. 35) são imperativos ao afirmarem que "o desafio de um projeto de Educação Ambiental é incentivar as pessoas a se reconhecerem capazes de tomar atitudes".

A inclusão dos professores no presente estudo foi devido ao entendimento de que eles são atores fundamentais para sensibilizar os alunos e ajudar a desenvolver ações pedagógicas no âmbito escolar (Tabela 2). Foram de fundamental importância conhecer e compreender como vem sendo trabalhado as questões ambientais dentro dessas duas instituições.

Tabela 2: Percepção de professores sobre a gestão de resíduos sólidos escolares de alunos da educação básica de duas escolas públicas em São Joaquim do Monte-PE.

Fonte: Elaborado a partir dos dados obtidos nesta pesquisa, 2018.

\begin{tabular}{|c|c|c|c|c|c|}
\hline \multirow[t]{2}{*}{ Item } & \multirow{2}{*}{$\begin{array}{c}\text { Questão } \\
\text { ATITUDE DE RESPOSTA }\end{array}$} & \multicolumn{4}{|c|}{ Atitude de Resposta (\%) } \\
\hline & & 1 & 2 & 3 & 4 \\
\hline \multirow{2}{*}{\multicolumn{2}{|c|}{$\begin{array}{l}\text { Q1. Você trabalha temas de Educação } \\
\text { Ambiental com seus alunos? }\end{array}$}} & Sim & Não & - & NR \\
\hline & & $61 \%$ & $39 \%$ & - & - \\
\hline \multirow{2}{*}{\multicolumn{2}{|c|}{$\begin{array}{l}\text { Q2. Você acha importante trabalhar e } \\
\text { inserir a temática ambiental no currículo } \\
\text { escolar? }\end{array}$}} & Sim & Não & - & NR \\
\hline & & $100 \%$ & 0 & - & - \\
\hline \multirow{2}{*}{\multicolumn{2}{|c|}{$\begin{array}{l}\text { Q3. Você já promoveu alguma ação } \\
\text { educativa ou projeto relacionado a coleta } \\
\text { seletiva e reciclagem no ambiente escolar? }\end{array}$}} & Sim & Não & $\begin{array}{l}\text { Já ouvi } \\
\text { Falar }\end{array}$ & NR \\
\hline & & $62 \%$ & $38 \%$ & - & - \\
\hline \multirow{2}{*}{\multicolumn{2}{|c|}{$\begin{array}{l}\text { Q4. Você acredita que a coleta seletiva } \\
\text { pode trazer benefícios dentro do espaço } \\
\text { escolar? }\end{array}$}} & Sim & Não & - & NR \\
\hline & & $100 \%$ & - & - & - \\
\hline \multirow{2}{*}{\multicolumn{2}{|c|}{$\begin{array}{l}\text { Q5. Em relação aos hábitos de seus } \\
\text { alunos sobre a separação do lixo: }\end{array}$}} & $\begin{array}{l}\text { Jogam no } \\
\text { chão }\end{array}$ & $\begin{array}{l}\text { Fazem } \\
\text { seleção }\end{array}$ & $\begin{array}{l}\text { Jogam na } \\
\text { lixeira }\end{array}$ & NR \\
\hline & & $34 \%$ & 0 & $66 \%$ & - \\
\hline \multirow{2}{*}{\multicolumn{2}{|c|}{$\begin{array}{l}\text { Q6. Sobre o gerenciamento dos resíduos } \\
\text { sólidos escolares, você acredita que é feito } \\
\text { de maneira correta? }\end{array}$}} & Sim & Não & - & NR \\
\hline & & $39 \%$ & $61 \%$ & - & - \\
\hline \multirow{2}{*}{\multicolumn{2}{|c|}{$\begin{array}{l}\text { Q7. Você acredita que a separação do } \\
\text { lixo seco e orgânico em escolas tem } \\
\text { contribuído para o reaproveitamento, } \\
\text { reciclagem e reutilização de resíduos? }\end{array}$}} & Sim & Não & - & NR \\
\hline & & $88 \%$ & $12 \%$ & - & - \\
\hline \multicolumn{2}{|c|}{$\begin{array}{l}\text { Q8. O que é necessário para inclusão da } \\
\text { Educação Ambiental nas escolas? }\end{array}$} & $\begin{array}{c}\text { Capacitações } \\
88 \%\end{array}$ & $\begin{array}{l}\text { Projetos } \\
2 \%\end{array}$ & Nãoabe & $\begin{array}{c}\text { NR } \\
-\end{array}$ \\
\hline
\end{tabular}

NR: não respondeu Q: questionamento/ questão 
No primeiro questionamento aos professores, $61 \%$ afirmaram trabalhar temas de Educação Ambiental e justificaram que a forma de conscientização de seus alunos é realizada por meio de textos, palestras, projetos, dinâmicas, filmes, pesquisas, aulas de campo e vídeos, enquanto 39\% não desenvolvia nenhum tipo de abordagem.

Para o questionamento $\mathrm{n}^{\circ} \mathbf{2}$, todos os professores responderam de forma afirmativa, e acham bastante importante inserir a temática ambiental no currículo escolar. Alguns ainda justificaram o porquê de sua importância (Quadro 2).

Quadro 2: Discurso de alguns professores sobre a importância da temática ambiental no espaço escolar.

\begin{tabular}{|c|c|}
\hline Entrevistado (a) & Justificativa \\
\hline Professor A & $\begin{array}{c}\text { "Para conscientizar os educandos sobre seu papel na gestão dos } \\
\text { resíduos sólidos e preservação ambiental" }\end{array}$ \\
\hline Professor B & $\begin{array}{l}\text { "Para conscientizar sobre a importância do meio ambiente para o } \\
\text { ser humano" }\end{array}$ \\
\hline Professor C & $\begin{array}{c}\text { "Devido a degradação do meio ambiente é necessário conscientizar } \\
\text { os jovens" }\end{array}$ \\
\hline Professor D & $\begin{array}{c}\text { "Não se pode ter a pretensão de trabalhar o aluno em sua inteireza } \\
\text { se não abordar o meio ambiente em que ele faz parte" }\end{array}$ \\
\hline Professor E & $\begin{array}{l}\text { "Inserir para formação de uma conscientização ética, a fim de } \\
\text { minimizar os efeitos e a degradação ambiental. }\end{array}$ \\
\hline Professor F & $\begin{array}{c}\text { "Para que seja feito um trabalho de conscientização prevenção e } \\
\text { preservação do meio ambiente" }\end{array}$ \\
\hline Professor G & $\begin{array}{c}\text { "Para que os alunos tenham consciência que suas ações causam } \\
\text { impactos no meio ambiente em que vivem. }\end{array}$ \\
\hline Professor $\mathbf{H}$ & $\begin{array}{c}\text { "Porque a perspectiva de vida depende das atuais ações desses } \\
\text { estudantes e seus familiares" }\end{array}$ \\
\hline Professor I & $\begin{array}{c}\text { "Para promover uma reflexão sobre o papel de cada um na } \\
\text { sociedade" }\end{array}$ \\
\hline Professor J & $\begin{array}{c}\text { "Para que eles possam conhecer causas e consequências } \\
\text { relacionadas ao mal comportamento do ser humano ao meio } \\
\text { ambiente" }\end{array}$ \\
\hline
\end{tabular}

As justificativas dadas pelo corpo docente de ambas as escolas, corrobora com as explicações dadas por Coelho et al. (2018) de que a escola é o local onde pode ser proporcionado os meios, para que seja compreendido o vínculo entre as atividades humanas e as questões ambientais. Neste contexto, $62 \%$ dos professores afirmaram já terem promovido, alguma ação educativa ou projeto relacionado à coleta seletiva e reciclagem no ambiente escolar.

Segundo os professores, as formas de trabalhar a Educação Ambiental escolar são através de projetos interdisciplinares, redes sociais, gincanas, projeto coleta seletiva transformando o lixo coletado em brinquedos, reciclagem na escola, canteiros com garrafas PETs, hortas sustentáveis, aulas de campo com visitas ao lixão da cidade etc. A execução de tais atividades dentro da escola não é o bastante, é preciso mudança de comportamento e um trabalho contínuo 
para que os próprios alunos possam transferir o que aprendeu junto a outros alunos, familiares e comunidade

Correia et al. (2016) apontam para o fato e já alertaram que temas sobre resíduos sólidos precisam fazer parte dos temas transversais, e de serem abordados em diversas disciplinas para que estes ensinamentos fazem parte do dia a dia do alunado, tornando a problemática percebida por aspectos e visões diferentes.

De uma forma geral todos os professores acreditam que a coleta seletiva pode trazer benefícios dentro das escolas. No entanto, poucos trabalharam ou trabalham com projetos que visem essa proposta permanente no espaço escolar.

O questionamento $\mathrm{n}^{0} 5$ indagou aos professores sobre 0 hábito dos alunos de como eles agiam no ambiente escolar, 34\% responderam que eles jogavam o lixo no chão e $66 \%$ jogavam na lixeira. Estes dados são contraditórios aos que se observou nas visitas in loco, uma vez que havia uma alta quantidade de resíduos lançados no chão das salas de aula, pátio e corredores.

No questionamento $n \div$ 6, foi perguntado aos educadores se eles tinham conhecimento de como é feito, o gerenciamento dos resíduos sólidos escolares. $61 \%$ dos entrevistados responderam que não sabia, e $39 \%$ respondeu que tinha conhecimento de como é feito o processo, e acreditam que é feito de maneira correta. Alguns ainda justificaram a inexistência da coleta seletiva dentro dessas escolas, fazendo com que todo tipo de resíduo, inclusive os orgânicos, fossem misturados junto ao lixo comum, produzido nos três horários de funcionamento.

O questionamento n 7 foi sobre a separação do lixo seco e orgânico dentro das escolas. É de extrema importância a separação desses resíduos principalmente quando instituições de ensino trabalham com reciclagem, reutilização e reaproveitamento. Apesar de $88 \%$ dos professores acreditarem que esse tipo de trabalho pode trazer diversos benefícios, não só na questão da reciclagem como reaproveitar o lixo orgânico para compostagem, e por consequência, pode trazer melhorias socioeconômicas, além de ser uma fonte de renda, $12 \%$ ainda acreditam que esse tipo de trabalho não fará diferença para escola nem para um meio ambiente mais equilibrado.

Quando indagados, no questionamento $\mathrm{n} \div 8$ sobre o que é necessário para inclusão da Educação Ambiental nas escolas, 88\% dos professores citaram o desenvolvimento de projetos que visem à participação de todos, escola e comunidade. É nítido que há uma falta de motivação nestes ambientes escolares, e que os trabalhos quando realizados, não perpassam de um pequeno público envolvendo alunos e professores, tais dados são parecidos a pesquisa de Dantas et al. (2015) quando estudaram a importância da Educação Ambiental no âmbito escolar. Além disso, Stangherlin e Specht (2014) afirmam que podem ser "contextualizados em todas as disciplinas, pois as temáticas sobre meio ambiente são transversais e englobam várias áreas do conhecimento".

Destaca-se que $12 \%$ dos professores entrevistados, afirmaram que 0 melhor a se fazer por parte das Secretarias de Educação Municipal e Estadual, 
é capacitar melhor os professores para que possam trabalhar de maneira mais efetiva, com a temática em sala de aula. Para este aspecto Araújo (2004, p. 77) detectou que as universidades não estavam preparando os futuros professores de forma adequada, e naquela época, alertou para que as universidades ficassem atentas "para alguns aspectos importantes na formação do professor para o agir profissionalmente diante das necessidades e exigências da atualidade".

\section{Considerações finais}

Os resultados do presente trabalho demonstram que para os alunos participantes de ambas escolas, em algum momento passado receberam orientações para descartar adequadamente os resíduos, incluído a coleta seletiva, mas não há por parte das escolas incentivo e persistência dos programas educativos para dar continuidade ao aprendizado do alunado.

Em relação aos professores de ambas escolas, há uma carência de capacitação em relação à Educação Ambiental. Cursos de atualização e/ou reciclagem poderiam ser oferecidos pelas próprias Secretarias de Educação (municipal ou estadual), como forma de incentivo para os professores trabalharem de maneira mais efetiva a Educação Ambiental no ambiente escolar.

Por fim, acredita-se que é preciso que ambas as instituições trabalhem de forma ativa, a temática Educação Ambiental com toda comunidade escolar a partir de estratégias que visem sensibilizar com eficácia os alunos para questões ambientais, inserindo os temas coleta seletiva, reciclagem e gerenciamento de resíduos sólidos, seja em sala de aula de maneira interdisciplinar e transdisciplinar, como também a promoção de palestras, debates, uso das Tecnologia da Informação e Comunicação (TICs) e outras medidas educativas nas escolas, que promovam a mudança de comportamento e atitudes, em prol de um meio ambiente mais equilibrado.

\section{Referências}

ALMEIDA, J.A. Gestão de resíduos sólidos em instituições de ensino: experiências internacionais e nacionais no município de Belo Jardim - PE. R. Gest. Sust. Ambient., v.7, p.467-485, 2018.

ABRELPE. ASSOCIAÇÃO BRASILEIRA DAS EMPRESAS DE LIMPEZA PÚBLICA E RESÍDUOS. Panorama dos resíduos sólidos no Brasil 2017. Disponível em: http://abrelpe.org.br/pdfs/panorama/panorama abrelpe 2017.pdf. Acesso em: 15 set. 2018.

ARAÚJO, M.I.O. A universidade e a formação de professores para a Educação Ambiental. RevBEA, v.0, p.71-78, 2004.

BARROS, R.M. Tratado sobre resíduos sólidos: gestão uso e sustentabilidade. Rio de Janeiro: Ed. Interciência, 2013. 374p. 
BEZERRA, Y.B.S.; PEREIRA, F.S.P.; SILVA, A.K.P.; MENDES, D.G.P.S. Análise da percepção ambiental de estudantes do ensino fundamental II em uma escola do município de Serra Talhada (PE). RevBEA, v.9, p.472-488. 2014.

BRASIL. Lei n.12.305, de 2 de agosto de 2010. Institui a Política Nacional de Resíduos Sólidos; altera a Lei n. 9.605, de 12 de fevereiro de 1998; e dá outras providências. Política Nacional de Resíduos Sólidos. Casa Civil Subchefia Para Assuntos Jurídicos. Disponível em: http://www.planalto.gov.br/ccivil 03/ ato2007-2010/2010/lei//12305.htm. Acesso em: 03 set. 2018.

BRASIL. Lei n. 9.795, de 27 abril de 1999. Dispõe sobre a Educação Ambiental, institui a Política Nacional de Educação Ambiental e dá outras providências. Política Nacional de Educação Ambiental. Disponível em: http://www.planalto.gov.br/ccivil 03/Leis/L9795.htm. Acesso em: 02 out. 2018.

BRASIL. Parâmetros Curriculares Nacionais - Meio Ambiente Saúde. Brasília: MEC/SEF, 1997. Disponível em: http://portal.mec.gov.br/seb/arquivos/pdf/ livro091.pdf. Acesso em: 02 maio. 2018.

COELHO, A.L.A.L.; ARAÚJO, L.A.S.; SILVA, A.W.P.; SANTOS, H.C.C.; COELHO, C. Educação para sustentabilidade e gestão pública em uma escola estadual na cidade de João Pessoa - PB. RIC@, v.12, p.23-38, 2018.

CORREIA, J.N.; FIGUEIREDO-DE-ANDRADE, C.A.; LIMA, N.B. Lixo e reciclagem: a percepção ambiental de estudantes de escolas públicas e privadas do município de bom jesus do Itabapoana (RJ). Perspectivas OnLine, v.15, p.53-65, 2016.

DANTAS, M.M.M.; MARTINS, J.G.S.; SOUZA, D.M.; GUIMARÃES, M.L.C.; SILVA, E.A. A importância da Educação Ambiental no amplo escolar. Cad. Agroecol., v.10, 2015. Disponível em: http://revistas.aba-agroecologia. org.br/index.php/cad/article/view/22284/12749. Acesso em: 15 jun. 2018.

FÉLIX, R.A.Z. Coleta seletiva em ambiente escolar. Rev. Eletrônica Mestr. Educ. Ambient., v.18, p.56-71, 2007.

GIL, A.C. Métodos e técnicas de pesquisa social. 6. ed. São Paulo: Atlas, 2012. 200p.

GOUVEIA, N. Resíduos sólidos urbanos: impactos socioambientais e perspectiva de manejo sustentável como inclusão social. Ciênc. Saúde Coletiva, v.16, p.1503-1510, 2012.

IBGE. INSTITUTO BRASILEIRO DE GEOGRAFIA ESTATÍSTICA. Censo 2017. Disponível em: https://cidades.ibge.gov.br/brasil/pe/sao-joaquim-do-monte/ panorama. Acesso em: 10 out. 2019.

MEIRELLES, M.S.; SANTOS, M.T. Educação Ambiental uma Construção Participativa. 2. ed. São Paulo, 2005. 87p.

MINAYO, M.C.S. O desafio da pesquisa social. In: MINAYO, M.C.S (org.) Pesquisa Social: teoria, método e criatividade. Petrópolis: Vozes, 2012. 108p. 
OLIVEIRA, T.K.S.; PINTO JÚNIOR, I.M. Política nacional de resíduos sólidos. Cad. Grad. -Ciênc. Exatas Tecnol., v.4, p. 77-84, 2018.

PORTELLA, M.O.; RIBEIRO, J.C.J. Aterros sanitários: aspectos gerais e destino final de resíduos. Rev. Direito Ambient. Soci., v.4, p.115-134, 2014.

RIBEIRO, L.C.S.; FREITAS, L.F.S.; CARVALHO, J.T.A.; OLIVEIRA FILHO, J.D. Aspectos econômicos e ambientais da reciclagem: um estudo exploratório nas cooperativas de catadores de material reciclável do Estado do Rio de Janeiro. Nova Econ., v.24, p.191-214, 2014.

SANTOS, A.; LIMA, M.L.B.; MACIEL, L.M.N.L.; PAZ, M.C.P; PAZ, R.J. A interdisciplinaridade na Educação Ambiental. Rev. Educ. Ambiental Ação, n.61, 2017.

SOARES, L. G. C; SALGUEIRO, A. A; GAZINEU, M. H. P. Educação Ambiental aplicada aos resíduos sólidos na cidade de Olinda, Pernambuco - um estudo de caso. Rev. Ciênc. \& Tecnol., v.1, p. 1-9, 2007.

STANGHERLIN, C.C.C.; SPECHT, S. Resíduos sólidos: percepções de alunos do Ensino Fundamental. Rev. Eletr. Gest., Educ. Tec. Ambient., v.18, p.919927, 2014.

THIOLLENT, M. Metodologia da pesquisa-ação. São Paulo: Cortez, 1986. $108 p$.

VILHENA, A. Lixo municipal: manual de gerenciamento integrado do CEMPRE. 4. ed. São Paulo: CEMPRE, 2018. 316p. 